development of the synaptic complex, and it is this disruption that elicits stereotyped pruning. So, the authors reasoned that in the absence of plexin A3 signalling, the mossy fibre synaptic complexes would continue to acquire more complex structures. Indeed, they found that in plexin A3 and neuropilin 2 (also required for stereotyped pruning) knockout mice, the mossy fibre boutons continued to mature.

The purpose of pruning is thought to be the fine-tuning of neural circuitry rather than the correction of errors. How pruning maintains appropriate connections while removing inappropriate ones remains to be resolved. However, the results reported by Liu, Low and colleagues provide insights into the molecular events that underlie the refinement of neural circuitry.

Samantha Barton

(2) References and links ORIGINAL RESEARCH PAPER Liu, X.-B., Low, L. K., Jones, E. G. \& Cheng, H.-J. Stereotyped axon pruning via plexin signaling is associated with synaptic complex elimination in the hippocampus. J. Neurosci. 25, 9124-9134 (2005)

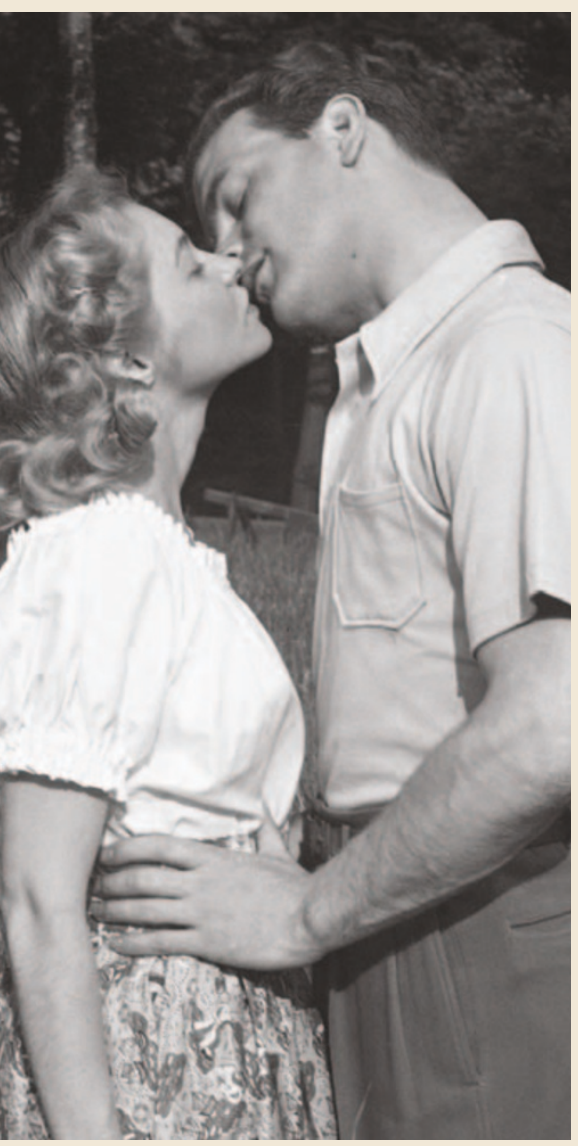

SYNAPTIC PLASTICITY

\section{More than mere coincidence}

A new form of synaptic plasticity is described by Lily Jan and colleagues in a report published recently in Cell. The remarkable phenomenon an NMDA ( $N$-methyl-D-aspartate) receptordependent long-term potentiation (LTP) of slow synaptic inhibition - might shorten the time window within which fast excitatory inputs that arrive at a similar time are perceived by the postsynaptic neuron as being coincident.

Excitatory synapses have typically been the focus of studies of synaptic plasticity, and many years of research have shown that the NMDAtype glutamate receptor serves as the 'coincidence detector', allowing the postsynaptic neuron to respond to inputs that arrive at about the same time with long-term changes in the strength of AMPA ( $\alpha$-amino-3-hydroxy-5-methyl-4isoxazole propionic acid) receptor-mediated fast excitation. Stimulations that cause the LTP of fast excitation can also lead to the long-term depression of fast inhibition.

Dendritic spines receive the vast majority of excitatory synapses, expressing both NMDA and AMPA receptors, whereas dendritic shafts play host to inhibitory synaptic transmission mediated by GABA ( $\gamma$-aminobutyric acid). So the finding that metabotropic $\mathrm{GABA}_{\mathrm{B}}$ (GABA type $B$ ) receptors and G-proteinactivated inwardly rectifying potassium (GIRK) channels - which together mediate slow synaptic inhibition - reside not only on dendritic shafts but also on the spines of dendrites caught the attention of the Jan laboratory. The group was curious to know whether the machinery in the spine for inducing synaptic plasticity of the AMPA receptormediated excitatory postsynaptic current (EPSC) could also affect the slow inhibitory postsynaptic current (sIPSC) mediated by GABA $_{\mathrm{B}}$ receptors.

The researchers recorded the sIPSC from CA1 pyramidal neurons of the rat hippocampus, looking at the effects of the coincidence detection of the synaptic release of glutamate and membrane depolarization. They were surprised to find that the signalling pathway that leads to LTP of the EPSC - NMDA receptor activation, $\mathrm{Ca}^{2+}$ influx and subsequent activation of the downstream second messenger $\mathrm{Ca}^{2+} /$ calmodulindependent protein kinase II - also causes LTP of the slow inhibition.

Jan's group collaborated with Robert Darnell to explore the effects of the neuronal RNAbinding protein Nova2 (neuro-oncological ventral antigen 2 ) - the target of autoimmune attack in a rare neurological disorder known as

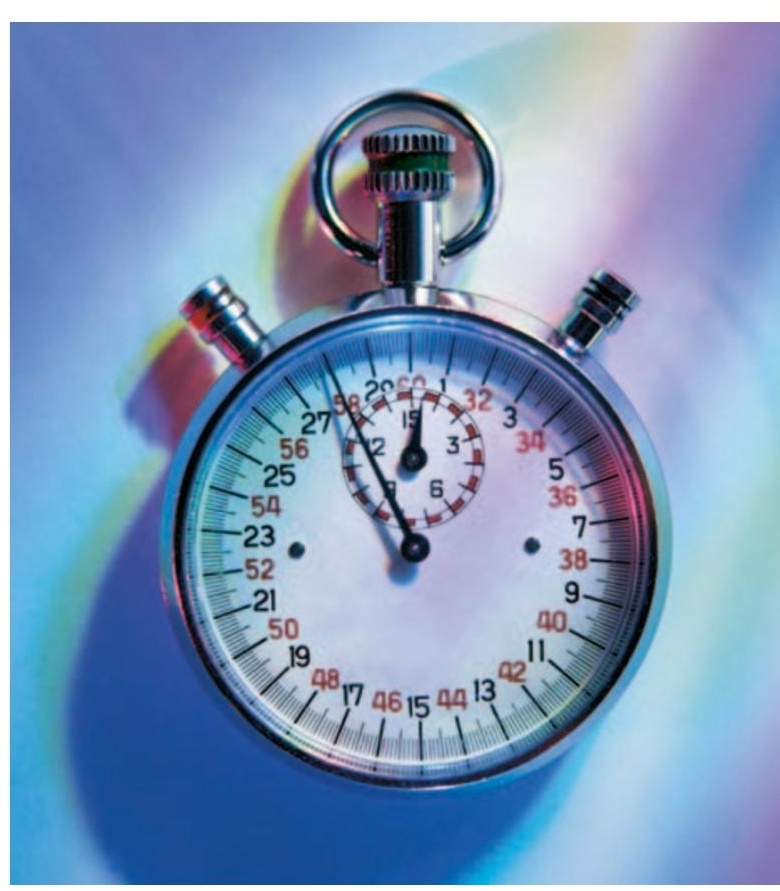

paraneoplastic opsoclonus myoclonus ataxia, which is characterized by abnormal motor inhibition - on the sIPSC. $\mathrm{GABA}_{\mathrm{B}}$ receptors, GIRK channels and several other proteins involved in inhibitory synaptic transmission are under the control of Nova2, which regulates the alternative splicing of a range of gene products. They found that the sIPSC was normal in Nova2null mice, but that LTP of the slow inhibition was lacking. Intriguingly, Nova2-null mice still showed LTP of the EPSC, suggesting that this protein is involved specifically in the activitydependent regulation of the efficacy of slow synaptic inhibition.

But why potentiate slow inhibition at the same time as fast excitation? The researchers speculate that potentiation of the sIPSC could sharpen the coincidence detection of excitatory events by reducing the impact of late-arriving inputs. This study undoubtedly raises a host of new questions about the ways in which neurons process multiple stimuli.

Rebecca Craven

\section{(2) References and links}

ORIGINAL RESEARCH PAPER Huang, C. S. et al. Common molecular pathways mediate long-term potentiation of synaptic excitation and slow synaptic inhibition. Cell 123, 105-118 (2005) FURTHER READING Ule, J. et al. CLIP identifies Nova-regulated RNA networks in the brain. Science 302, 1212-1215 (2003) | Ule, J. et al. Nova regulates brain-specific splicing to shape the synapse. Nature Genet. 37, 844-852 (2005)

WEB SITE

The Jan Laboratory: http://www.ucsf.edu/jan/ 